\title{
Práticas de Gerenciamento de Projetos e PMO em hospitais: revisão integrativa da
}

\section{literatura}

\author{
Project Management and PMO practices in hospitals: an integrative literature review \\ Prácticas de gestión de proyectos y PMO en hospitales: una revisión integradora de la literatura
}

Recebido: 13/12/2021 | Revisado: 18/12/2021 | Aceito: 20/12/2021 | Publicado: 03/01/2022

\author{
André Luiz França Alves \\ ORCID: https://orcid.org/0000-0003-2491-7633 \\ Universidade Federal de Sergipe, Brasil \\ E-mail: andrelfalves@outlook.com \\ Simone de Cassia Silva \\ ORCID: https://orcid.org/0000-0001-6076-9071 \\ Universidade Federal de Sergipe, Brasil \\ E-mail: scassia@ academico.ufs.br \\ Marco Antônio Prado Nunes \\ ORCID: https://orcid.org/0000-0001-5244-5843 \\ Universidade Federal de Sergipe, Brasil \\ E-mail: nunes.ma@ufs.br
}

\begin{abstract}
Resumo
O objetivo deste estudo é verificar o que foi desenvolvido na literatura científica mundial em práticas de gerenciamento de projetos (GP) e implantação de Escritório de Gerenciamento de projetos (EGP) em hospitais. Tratase de uma revisão integrativa da literatura, tendo como amostra final 19 artigos; os resultados foram analisados com relação ao ano, local do estudo, boas práticas, ferramentas e desafios. Também foi feita a busca por consonância entre os achados e as funções tipológicas desenvolvidas e defendias por Hill (2008) que compõe as funções de um EGP; pode ser visto que dentre os 19 artigos selecionados, todos apresentam práticas que permeiam umas das 5 funções de HILL (2008). Desse modo, é possível concluir que a implantação de um EGP em hospitais é promissora ao ser considerado os resultados das práticas nacionais e internacionais.

Palavras-chave: Gestão da informação; Projetos; Administração de serviços de saúde; Escritório de gerenciamento de projetos.
\end{abstract}

\begin{abstract}
The aim of this study is to verify what has been developed in the world scientific literature in project management practices (GP) and implementation of Project Management Office (EGP) in hospitals. This is an integrative literature review, with a final sample of 19 articles; the results were results regarding the year, place of study, best practices, tools and challenges. A search was also made for consonance between the findings and the typological functions developed and defended by Hill (2008), which make up the functions of an EGP; it can be seen that among the 19 selected articles, all present practices that permeate one of the 5 functions of HILL (2008). Thus, it is possible to conclude that the implementation of an EGP in hospitals is promising when considering national and international results.
\end{abstract}

Keywords: Information management; Projects; Health services administration; Project management office.

\section{Resumen}

El objetivo de este estudio es verificar lo desarrollado en la literatura científica mundial en las prácticas de gestión de proyectos (GP) y la implementación de la Oficina de Gestión de Proyectos (EGP) en hospitales. Se trata de una revisión de literatura integradora, con una muestra final de 19 artículos; los resultados fueron resultados respecto al año, lugar de estudio, mejores prácticas, herramientas y desafíos. También se buscó la consonancia entre los hallazgos y las funciones tipológicas desarrolladas y defendidas por Hill (2008), que conforman las funciones de un EGP; se puede observar que entre los 19 artículos seleccionados, todos presentan prácticas que permean una de las 5 funciones de HILL (2008). Así, es posible concluir que la implementación de un EGP en hospitales es prometedora al considerar los resultados nacionales e internacionales.

Palabras clave: Gestión de la información; Proyectos; Administración de servicios de salud; Oficina de gestión de proyectos. 


\section{Introdução}

Os hospitais, encaram diversos desafios em torno das limitações na administração e prestação de cuidados (Aubry et. al., 2018). Alguns aspectos, tais como controle e eficiência na gestão, sistemas de informações, acompanhamento e avaliação do desempenho, entre outros, não são observados nas organizações hospitalares brasileiras de forma geral (Saleem et. al, 2020). Uma das práticas efetivas para dar suporte à gestão nas instituições, incluindo as hospitalares, é a administração de projetos. Instituições de alto desempenho estão evidenciando que a aderência à gestão profissional de projetos, programas e portfólio reduz riscos, custos e melhora taxas de êxito dos projetos e programas (Mamédio et. al., 2020). A relevância de aprimorar os resultados dos projetos e padronizar os esforços de gerenciamento de projetos, programas e portfólio, em regra, orienta as organizações a pensarem em uma área ou um time de pessoas para fazer esse trabalho (Almeida, 2017).

Uma das propostas para que se logre êxito na construção e consolidação de boas práticas é a instalação de um escritório de projetos (EGP) (PMI, 2018). O EGP é uma área ou grupo de pessoas agrupadas no mesmo ambiente físico ou não, que se torna responsável por garantir que as disciplinas de gestão de projetos, programas e portfólio sejam executadas de forma profissional, fazendo a direção, gestão e avaliação das iniciativas nessas áreas, visando garantir a melhoria dos resultados organizacionais que dependem de projetos (Almeida, 2017). Pesquisas anteriores mostraram que um número crescente de organizações está estabelecendo EGP (Jalal, Koosha, 2015; Bredillet et al., 2018) e os pesquisadores ainda definiram diferentes categorias de funções de EGP (Rad, Levin, 2002).

Nas funções de alinhamento de negócios encontram-se o gerenciamento de portfólio de projetos, gerenciamento de relacionamento com o cliente, fornecedor e contratado, gestão de relacionamento e gestão de desempenho de negócios (Kerzner, 2017). Tais funções permitem que o EGP receba orientações de desempenho de negócios e as traduza para aplicação no gerenciamento de projetos em meio ao ambiente organizacional (Artto et al., 2011; Wysocki, 2013). Essa função representa uma gama de atividades de EGP do alinhamento distinto da estratégia de negócios com o desempenho do projeto para a interpretação e implementação da direção às vezes mais sutil e orientação política que emana da diretoria executiva (Kerzner, 2017). Bolles e Hubbard (2007) defendem que absorver as técnicas de gerenciamento de projetos exige uma avaliação a respeito de como a instituição atinge os fins e desenvolvem suas estratégias de negócios. Essa estratégia de negócios é tradicionalmente operacionalizada em projetos, programas e portfólio.

Para Morris e Jamelson (2005), para uma efetiva governança corporativa é imprescindível que as corporações tenham em mente sua estratégia de negócios associada à gestão de portfólio de projetos. Faicd (2005) descreve a gestão de portfólio como um inventário de projetos e/ou programas que são agrupados para facilitar o gerenciamento dos objetivos estratégicos. Para Archibald (2003), a gestão de portfólio necessita oferecer suporte à missão e às estratégias de crescimento. Para Rad e Levin (2006), a gestão de portfólio é parte de um sistema essencial para as organizações que são transparentes quanto à informação de seus projetos.

As funções de suporte técnico, composta por mentoreamento, planejamento de projetos, auditoria de projeto e recuperação de projetos, propiciam que o EGP auxilie os gerentes de projeto a trazerem projetos de sucesso com confiabilidade e regularidade previstas (Hill, 2008). Essa função fornece suporte focado no nível do projeto, mas o faz em conjunto com interesses comerciais distintos. Na medida em que os projetos representam o negócio da organização relevante, as funções de suporte técnico garantem que o negócio seja realizado de maneira oportuna e profissional e em cumprimento às obrigações contratuais e regulamentares (Rad, Levin, 2002; Levin, 2010). É possível observar que o desenvolvimento das funções de EGP remete o suporte constante e presente aos gerentes de projeto, seja na centralização das informações estratégicas, seja nas auditorias e revisões de qualidade (Bracui, 2012; Hobbs, Aubry, 2007; Artto et al., 2011; Wysocki, 2013; Kerzner, 2017). Para Wysocki (2009), a função de suporte a projetos engloba todos os serviços de apoio administrativo para ajudar o gerente e a equipe a entregar o projeto no orçamento. Para o autor, essa função fornece o apoio à equipe inteira do projeto numa tentativa 
de remover o máximo de trabalho sem valor agregado a um custo menor. Como o trabalho caracteriza-se eminentemente por ser administrativo e necessário, a equipe inteira do projeto pode efetivamente focar em assuntos que tragam valor dentro dos objetivos e metas e que estejam em conformidade às suas aptidões.

Para o Hill (2008), as funções de integração de recursos - gerenciamento de recursos, treinamento e educação, desenvolvimento de carreira e capacitação de equipe - permitem que o EGP identifique os requisitos e estabeleça a capacidade para o desdobramento das competências da equipe no ambiente de projetos. Essa função permite que o EGP represente os interesses do time de projeto dentro da corporação. Ele também permite que o EGP defina e gerencie as necessidades da equipe do projeto dentro do ambiente de gerenciamento de projetos (Desouza, Evaristo, 2006; Andersen et al., 2007; Hobbs, Aubry, 2007; Artto et al., 2011; Wysocki, 2013). Normalmente fará interface com o departamento de recursos humanos (RH) para adquirir e atribuir recursos, mas esse esforço começa com a facilitação da deliberação com os gerentes seniores para obter aprovação inicial de aquisição de recursos e subsequente alocação de recursos, uma função do desempenho empresarial (Kerzner, 2017).

De modo progressivo, as organizações se sentem pressionadas a realizar com mais maturidade seus processos orientados para pessoas. A função recursos humanos do EGP compreende gestão de recursos, mentoring, treinamentos, planos de carreiras e suporte ao desenvolvimento de equipes de projetos (Barcui, 2012; Kerzner, 2017). Segundo Bolles e Hubbard (2007) e Kerzner (2000), uma organização que pretenda atingir objetivos estratégicos significantes necessita desenvolver programas compreensivos de educação e treinamentos que efetivamente proporcionem conhecimentos e habilidades aos gerentes e à equipe quanto aos aspectos técnicos, humanos e, principalmente, de gerenciamento de projetos (Desouza, Evaristo, 2006; Andersen et al., 2007; Hobbs, Aubry, 2007)

Segundo Hill (2008), as funções de gerir a infraestrutura - governança do projeto, avaliação, organização e estrutura e supervisão cruzada de projetos e apoio a projetos - permitem que o EGP forneça supervisão de projetos cruzados e suporte aos projetos. Esta capacidade funcional é estabelecida a fim de que os gerentes de projetos individuais não sejam sobrecarregados com a configuração da infraestrutura para cada esforço de projeto encontrado, com o propósito de que a organização relevante ganhe benefícios com a implantação centralizada de atividades de supervisão do projeto que teriam potencial de ser repetidas com abordagens diferentes por cada gerente de projeto. O EGP pode começar a examinar os impactos do desempenho do negócio como o planejamento da infraestrutura de gerenciamento de projetos. É realizado, principalmente ao longo das linhas de eficiência empresarial, mas também com atenção à capacidade de gerir os projetos (Kerzner, 2017).

A gestão da infraestrutura do gerenciamento de projetos está contemplada nas áreas da governança corporativa relacionadas às atividades de projeto e programas (Artto et al., 2011; Wysocki, 2013; Kerzner, 2017). A governança eficiente, eficaz e efetiva do gerenciamento de projetos almeja garante que o portfólio de projetos esteja alinhado aos objetivos estratégicos da organização, bem como seja entregue eficiente e sustentavelmente (Andersen et al, 2007). A governança do gerenciamento de projetos suporta também que todos os agentes interessados sejam providos das informações relevantes e confiáveis na ocasião adequada (APM, s.d.). As funções do grupo "práticas de gerenciamento" - gerenciamento de metodologia de projeto, ferramentas de gerenciamento de projeto, padrões e métricas e gerenciamento de conhecimento do projeto - permitem que o gerente de projeto e a equipe do projeto gerenciem e conduzam o projeto com eficácia (Wysocki, 2013; Kerzner, 2017). O conteúdo da orientação de práticas de gestão é geralmente representativo na natureza técnica do negócio da organização (Hill, 2008). A natureza do trabalho em gerenciamento de projetos, em especial no EGP, está associada ao uso constante de metodologias, das suas melhores práticas, da aplicação de indicadores, processos e tecnologias que permitem melhor desempenho (Barcui, 2012).

Desse modo, Hill (2014) contemplou cinco categorias de funções do EGP, incluindo "práticas de gerenciamento", "gerenciamento de infraestrutura", "integração de recursos", "suporte técnico" e "alinhamento de negócios". Cada uma dessas 
funções foi respectivamente dividida em uma série de sub funções com taxas de frequência variadas na literatura relacionada. Bouer e Carvalho (2005) consideram que o EGP precisa estar aderente ao papel do gerenciamento de projetos dentro da estratégia corporativa, para refletir a estrutura organizacional e a alocação de projetos.

A partir do contexto supracitado da importâncias das práticas de gerenciamento de projetos e funções do EGP, em especial sob a perspectiva de Hill (2008), esse trabalho teve como objetivo a busca, por meio de uma revisão integrativa, de evidências de práticas nacionais e internacionais de gerenciamento de projetos e EGP no âmbito hospitalar de modo a compreender quanto desses experiências compreendem a tipologia de Hill (2008).

\section{Metodologia}

A metodologia utilizada neste artigo trata-se de uma Revisão Integrativa, um método de pesquisa que permite a síntese de vários estudos publicados e que possibilita trazer conclusões gerais a respeito de uma área de estudo bem definida. A Revisão integrativa tem etapas bem definidas, que são: definição da pergunta norteadora, coleta de dados, avaliação dos dados, análise e interpretação de dados e a apresentação da revisão (Mendes, et al, 2008). Por se tratar de uma revisão integrativa da literatura, não foi necessária a aprovação do estudo pelo comitê de ética em pesquisa, segundo a Resolução 466/12 do Ministério da Saúde.

O processo de seleção dos artigos foi realizado com a aplicação de duas estratégias de busca. A motivação da criação de ambas strings de pesquisa foi alcançar o maior número de trabalhos possíveis. Pois, há diversas práticas, metodologias e experiências distintas de acordo com cada região ou realidade profissional.

Neste contexto, o atual trabalho busca executar uma revisão integrativa que contemple boas práticas, ferramentas e desafios da gestão de projetos e Escritórios de gerenciamento de projetos na área hospitalar. Como ponto de partida para a revisão foi formulada a pergunta de investigação em formato PI[C]O (População, Intervenção, Comparação e Desfecho) (Dos Anjos et. al., 2021): Em relação ao ambiente hospitalar (Population) quais práticas de gestão de projetos impactam gerencialmente (Outcome) e quais lacunas gerenciais por parte dos projetos de serviços de saúde essas práticas atendem (Intervention)? Para este estudo foram pesquisadas nove bases de periódicos relevantes em âmbito acadêmico: Scopus, Web of Science, SciELO, SAGE, Science Direct, Emerald, Francis \& Taylor, Indescience e BVS, com os termos escolhidos: Gerenciamento de projetos e Escritório de Gerenciamento de projetos.

O primeiro termo, "Gerenciamento de projetos em saúde" consiste no cerne central da problemática. O segundo termo, "Escritório de Gerenciamento de Projetos em saúde", foi escolhido devido ao entendimento de que projetos, enquanto empreendimento vinculados a interesses estratégicos e promotores da mudança, permitem evidenciar duas fases do cenário hospitalar: o anterior e o posterior à implementação do projeto (Mamédio, 2020). Essas fases ajudam a revelar os problemas específicos que motivaram a busca por aprimoramento da gestão hospitalar nas instituições estudadas, bem como os resultados, positivos e negativos, da implementação dos projetos.

Logo, "Gerenciamento de projetos em saúde" e "Escritório de Gerenciamento de projetos em saúde" foram incorporados na pesquisa da seguinte forma: ("gestão de projetos" OR "gerenciamento de projetos" OR "Project management" OR "Gestión de proyectos" OR "Gestion de projet" OR "Projektmanagement") AND (hospital OR hospitais OR hôpital OR Krankenhaus); ("PMO", "Project management office" OR maturity in project management OR typology of project office OR project management office category OR assignment of the project office OR benefits of the project office OR portfolio management) AND (health care OR hospital). e "Projetos".

Os critérios de exclusão foram: editoriais, monografias, dissertações, teses, cartas, comentários, artigos de revisão, artigos cujo texto completo não estava acessível, relatórios, além dos que não atenderam aos critérios supracitados, os artigos que, após a realização da leitura dos artigos completos, não atenderam ao objetivo da pesquisa. 
Assim buscou-se verificar a aderência com a temática da pesquisa proposta, ou seja, Gestão de Projetos e Escritório de Gerenciamento de Projetos aplicados ao ambiente hospitalar, selecionando aqueles que apresentassem identificação, chegando-se ao número final de 19 selecionados para compor o estudo. O desenho da revisão integrativa pode ser observado na Figura 1.

Figura 1: Fluxograma do processo de seleção dos estudos para a revisão integrativa.
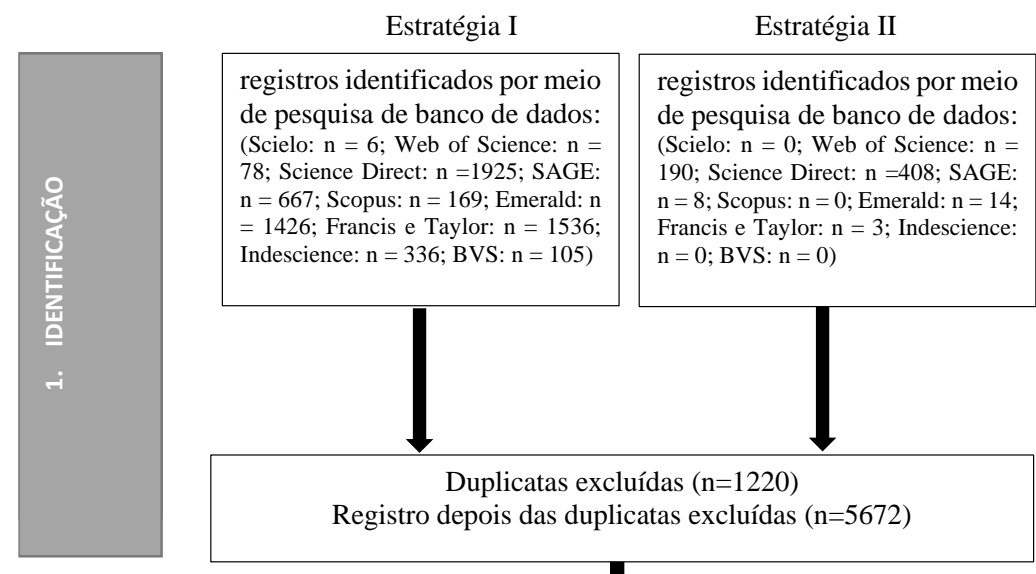

Duplicatas excluídas $(\mathrm{n}=1220)$
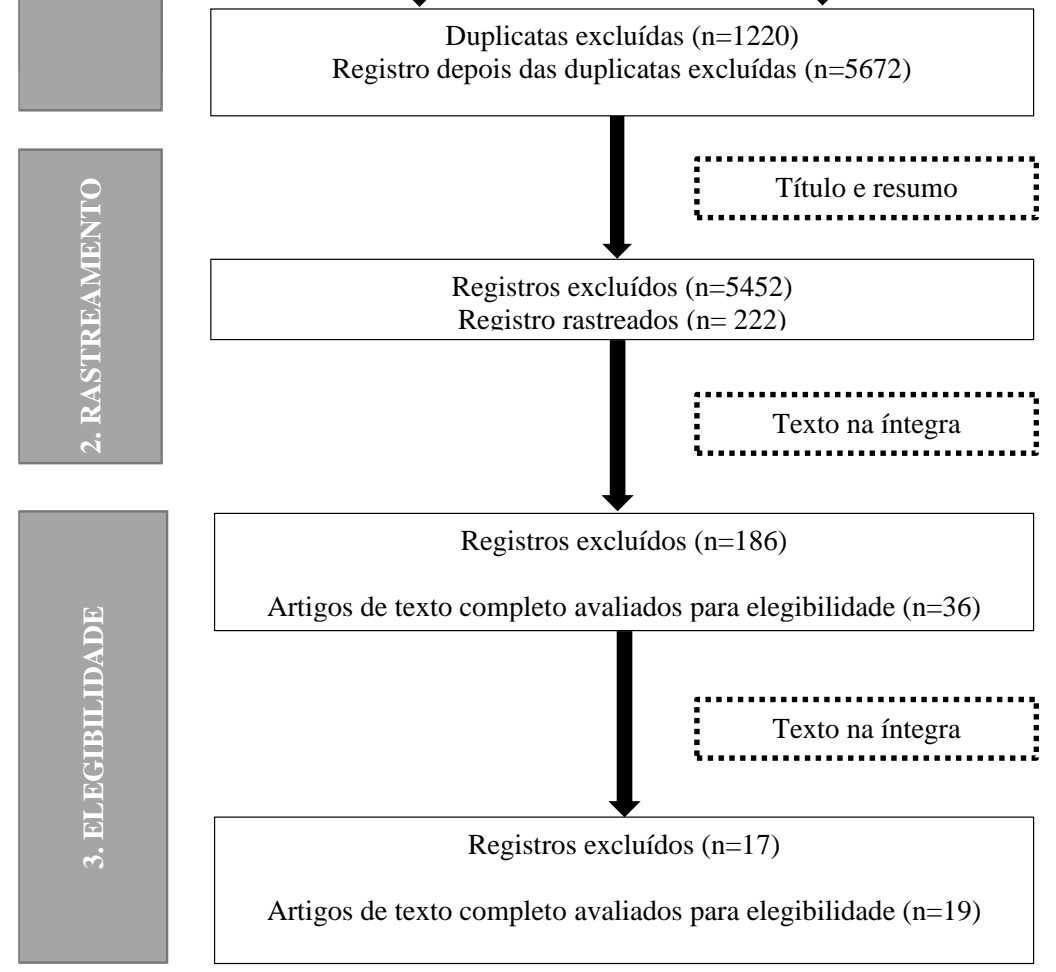

Registros excluídos $(n=17)$

Artigos de texto completo avaliados para elegibilidade $(n=19)$

Fonte: Autores (2021).

A Figura 1 ilustra todo o processo, desde os primeiros resultados de identificação, até a composição final do núcleo de elegibilidade. Para facilitar a apresentação do processo de seleção dos estudos incluídos, foram aplicadas as recomendações do Preferred araeporing items for Systematic reviews and Meta-Analyses (PRISMA). Tal escolha justifica-se pela ampla aplicabilidade do PRISMA (Moher, 2009).

\section{Resultados e Discussão}

Em relação aos artigos elegíveis, observa-se a predominância de periódicos associados às áreas de saúde (journal nursing management, International Journal of Environmental Research and Public Health, The Health Care Manager, Iranian Journal of Public Health, Revista Brasileira de Enfermagem Online, Biopreservation and Biobanking, International Journal of 
Health Care Quality Assurance, Journal of Hospital Librarianship, Facilities, Revista Gaúcha de Enfermagem) e administração (Journal of General Management). Ressalta-se ainda a ocorrência de cinco publicações em periódicos da área de gerenciamento de projetos (International Journal of Project Management, Project Management Journal e International Journal of Managing Projects in Business), revelando possibilidades quanto à convergência de temáticas de gestão hospitalar e metodologias de gerenciamento de projetos. Há, também, uma publicação em um periódico da área de informática médica (ACTA informatica médica).

Podemos inferir que há evidências, em termos de pesquisa, a respeito das boas práticas, ferramentas e desafios em gerenciamento de projetos e PMO na área hospitalar. Os resultados provenientes do levantamento evidenciaram uma diversidade de assuntos referentes à administração de projetos, programas e portfólios, associados especialmente às boas práticas em gestão de projetos cujas pesquisas selecionadas elucidam, conforme Quadro 1.

Quadro 1: Revisão integrativa das publicações sobre o EGP e o GP em hospitais.

\begin{tabular}{|c|c|c|c|c|c|c|}
\hline $\begin{array}{l}\text { Base de } \\
\text { dados }\end{array}$ & ID & Periódico & Autor(es) / ano & Título & Objetivo & Conclusão \\
\hline SAGE & A1 & $\begin{array}{l}\text { Biopreservation } \\
\text { and Biobanking }\end{array}$ & $\begin{array}{c}\text { Carsten Schultz, Jan } \\
\text { Graw, Søren } \\
\text { Salomo, and } \\
\text { Alexander Kock, } \\
2019 \text { / } \\
\text { Alemanha }\end{array}$ & $\begin{array}{c}\text { Como o } \\
\text { gerenciamento de } \\
\text { projetos e o } \\
\text { envolvimento da } \\
\text { alta administração } \\
\text { afetam a capacidade } \\
\text { de inovação das } \\
\text { organizações de } \\
\text { serviços } \\
\text { profissionais - um } \\
\text { estudo empírico em } \\
\text { hospitais }\end{array}$ & $\begin{array}{l}\text { Avaliar o impacto da } \\
\text { profissionalização do } \\
\text { gerenciamento } \\
\text { projetos de } \\
\text { envolvimento da alta } \\
\text { administração } \\
\text { capacidade de inovação } \\
\text { das organizações de } \\
\text { serviços profissionais. }\end{array}$ & $\begin{array}{l}\text { Os hospitais são mais } \\
\text { capazes de implementar } \\
\text { inovações médicas e } \\
\text { expandir o escopo de seu } \\
\text { portfólio de serviços } \\
\text { médicos se tiverem um alto } \\
\text { nível de profissionalização } \\
\text { em gerenciamento de } \\
\text { projetos. }\end{array}$ \\
\hline PUBMED & A2 & $\begin{array}{c}\text { The health care } \\
\text { manager }\end{array}$ & $\begin{array}{l}\text { Lavoie-Tremblay, } \\
\text { M., Aubry, M., } \\
\text { Richer, M. C., \& } \\
\text { Guylaine, C. Y. R., } \\
\text { (2018) / Canada }\end{array}$ & $\begin{array}{l}\text { Estratégias de um } \\
\text { PMO de saúde para } \\
\text { mudança e melhoria } \\
\text { contínua }\end{array}$ & $\begin{array}{l}\text { Ampliar a compreensão } \\
\text { dos mecanismos de } \\
\text { melhoria contínua } \\
\text { usados pelos PMOs e } \\
\text { descrever as estratégias } \\
\text { do PMO para mudança } \\
\text { contínua e melhoria } \\
\text { contínua no contexto de } \\
\text { grandes transformações } \\
\text { na área de saúde }\end{array}$ & $\begin{array}{l}\text { Os escritórios de apoio à } \\
\text { transição são estruturas } \\
\text { necessárias durante } \\
\text { grandes mudanças em uma } \\
\text { organização de saúde, a } \\
\text { fim de limitar os altos } \\
\text { níveis de rotatividade: } \\
\text { mandato claro do PMO } \\
\text { alocação do líder do PMO, } \\
\text { alocação dos recursos } \\
\text { certos, apoio da alta } \\
\text { administração, centro de } \\
\text { apoio disponível à linha de } \\
\text { frente e apoio a todo o } \\
\text { ciclo de vida do projeto. }\end{array}$ \\
\hline $\begin{array}{l}\text { Science } \\
\text { Direct }\end{array}$ & A3 & $\begin{array}{l}\text { International } \\
\text { Journal of } \\
\text { Project } \\
\text { Management, }\end{array}$ & $\begin{array}{c}\text { Aubry, M., Richer, } \\
\text { M. C., \& Lavoie- } \\
\text { Tremblay, M. } \\
\text { (2014) / Canada }\end{array}$ & $\begin{array}{l}\text { Desempenho de } \\
\text { governança em } \\
\text { ambiente complexo: } \\
\text { o caso de uma } \\
\text { grande } \\
\text { transformação em } \\
\text { um hospital } \\
\text { universitário }\end{array}$ & $\begin{array}{l}\text { Lançar um olhar novo e } \\
\text { relevante para o estudo } \\
\text { do desempenho das } \\
\text { organizações engajadas } \\
\text { na gestão de projetos. }\end{array}$ & $\begin{array}{l}\text { Há paradoxos entre os } \\
\text { executivos e o PMO em } \\
\text { relação ao desempenho do } \\
\text { PMO. Isso lança luz não } \\
\text { apenas sobre os paradoxos, } \\
\text { mas também sobre o } \\
\text { processo dinâmico } \\
\text { relacionado avaliação de } \\
\text { desempenho em um } \\
\text { projeto de transformação. }\end{array}$ \\
\hline Science & A4 & Procedia & do Rosário & Indicadores de & Avaliar a relevância & Com base no triângulo do \\
\hline
\end{tabular}




\begin{tabular}{|c|c|c|c|c|c|c|}
\hline Direct & & Technology & $\begin{array}{l}\text { Bernardo, M., } \\
\text { (2014) / Portugal }\end{array}$ & $\begin{array}{l}\text { projeto para } \\
\text { melhorar a } \\
\text { governança de } \\
\text { projetos }\end{array}$ & $\begin{array}{l}\text { percebida dos diferentes } \\
\text { indicadores de projetos, } \\
\text { no contexto de } \\
\text { governança de projetos }\end{array}$ & $\begin{array}{l}\text { ouro -custos, tempo e } \\
\text { qualidade - o conjunto de } \\
\text { indicadores mais relevante } \\
\text { é aquele relacionado aos } \\
\text { custos, seguido pelo } \\
\text { tempo. Os indicadores de } \\
\text { sustentabilidade } \\
\text { satisfação apresentam } \\
\text { relevância inferior aos de } \\
\text { desempenho e são mais } \\
\text { relevantes para a alta } \\
\text { administração do que para } \\
\text { os demais stakeholders. }\end{array}$ \\
\hline $\begin{array}{l}\text { Science } \\
\text { Direct }\end{array}$ & A5 & $\begin{array}{c}\text { Procedia } \\
\text { computer science }\end{array}$ & $\begin{array}{c}\text { Santos, V., \& } \\
\text { Varajão, J. (2015) / } \\
\text { Portugal }\end{array}$ & $\begin{array}{l}\text { PMO como } \\
\text { ingrediente chave } \\
\text { para o sucesso de } \\
\text { projetos do setor } \\
\text { público }\end{array}$ & $\begin{array}{l}\text { Discutir a seguinte } \\
\text { pergunta de pesquisa } \\
\text { "Quais condições } \\
\text { organizacionais } \\
\text { justificam e não } \\
\text { justificam a criação de } \\
\text { um PMO de TI? }\end{array}$ & $\begin{array}{l}\text { Cada cenário de } \\
\text { implementação é adequado } \\
\text { para diferentes áreas e } \\
\text { reflete diferentes níveis de } \\
\text { maturidade em } \\
\text { gerenciamento de projetos }\end{array}$ \\
\hline SAGE & A6 & $\begin{array}{c}\text { Journal of } \\
\text { General } \\
\text { Management }\end{array}$ & $\begin{array}{l}\text { Srivannaboon, S., \& } \\
\text { Southall, P. (2011) / } \\
\text { Tailândia }\end{array}$ & $\begin{array}{c}\text { Um estudo } \\
\text { exploratório sobre o } \\
\text { valor do } \\
\text { gerenciamento de } \\
\text { projetos para a } \\
\text { administração } \\
\text { hospitalar na } \\
\text { Tailândia }\end{array}$ & $\begin{array}{l}\text { Fornecer alguns insights } \\
\text { sobre os fatores que } \\
\text { auxiliam e dificultam os } \\
\text { médicos em suas funções } \\
\text { como administradores } \\
\text { hospitalares em relação } \\
\text { ao gerenciamento de } \\
\text { projetos e como o } \\
\text { gerenciamento de } \\
\text { projetos pode agregar } \\
\text { valor e eficiência para } \\
\text { melhorar suas operações }\end{array}$ & $\begin{array}{l}\text { Existem grandes } \\
\text { oportunidades no ambiente } \\
\text { hospitalar para utilizar a } \\
\text { gestão de projetos, que vão } \\
\text { desde os usos tradicionais } \\
\text { de projetos, como a uso de } \\
\text { sistemas de registro } \\
\text { eletrônico, integracões de } \\
\text { redes de entrega e } \\
\text { programas de controle de } \\
\text { qualidade, até um novo } \\
\text { paradigma de utilização de } \\
\text { gestão de projetos no nível } \\
\text { estratégico }\end{array}$ \\
\hline PUBMED & A8 & $\begin{array}{c}\text { The health care } \\
\text { manager }\end{array}$ & $\begin{array}{c}\text { Giasson, L., (2019) / } \\
\text { Canada }\end{array}$ & $\begin{array}{l}\text { O melhor dos dois } \\
\text { modelos } \\
\text { Componentes-chave } \\
\text { de um modelo de } \\
\text { escritório de } \\
\text { gerenciamento de } \\
\text { projeto híbrido de } \\
\text { sucesso em uma } \\
\text { organização de } \\
\text { saúde }\end{array}$ & $\begin{array}{l}\text { Descrever o PMO model } \\
\text { híbrido no Ontario } \\
\text { Shores Center for Mental } \\
\text { Health Sciences (Ontario } \\
\text { Shores), com um foco } \\
\text { particular na criação da } \\
\text { rede PM, que foi } \\
\text { considerada } \\
\text { componente-chave para } \\
\text { preencher a lacuna entre } \\
\text { projetos }\end{array}$ & $\begin{array}{l}\text { Os benefícios surgiram da } \\
\text { incorporação dos gerentes } \\
\text { de projeto em unidades de } \\
\text { portfólio. Esses benefícios } \\
\text { incluíram (1) gerentes de } \\
\text { projeto que construíram } \\
\text { relacionamentos } \\
\text { colaborativos, } \\
\text { compreenderam o negócio } \\
\text { e se acostumaram a } \\
\text { entregar no ambiente de }\end{array}$ \\
\hline
\end{tabular}


Research, Society and Development, v. 11, n. 1, e125111124666, 2022

(CC BY 4.0) | ISSN 2525-3409 | DOI: http://dx.doi.org/10.33448/rsd-v10i4.24666

\begin{tabular}{|c|c|c|c|c|c|c|}
\hline & & & & & descentralizados. & $\begin{array}{l}\text { destino; (2) agilidade na } \\
\text { tomada de decisões e a } \\
\text { capacidade de gerir com } \\
\text { mais eficácia as mudanças } \\
\text { do projeto; e (3) menos } \\
\text { sobrecarga de PMO central } \\
\text { devido aos gerentes de } \\
\text { projeto reportando em } \\
\text { portfólios, com economia } \\
\text { especialmente no espaço } \\
\text { de relatório, uma vez que } \\
\text { relatórios e governança } \\
\text { menos centralizados são } \\
\text { obrigatórios }\end{array}$ \\
\hline BVS & A10 & $\begin{array}{l}\text { Online Brazilian } \\
\text { Journal of } \\
\text { Nursing }\end{array}$ & $\begin{array}{l}\text { Freire, E. M. R., } \\
\text { Batista, R. C. R., \& } \\
\text { Martinez, M. R. } \\
\text { (2016/ Brasil }\end{array}$ & $\begin{array}{l}\text { Gerenciamento de } \\
\text { projetos voltado } \\
\text { para acreditação } \\
\text { hospitalar: } \\
\text { estudo de caso }\end{array}$ & $\begin{array}{l}\text { Descrever } \\
\text { implementação dos } \\
\text { processos de Gestão de } \\
\text { Projetos baseado nas } \\
\text { premissas do Project } \\
\text { Management Body of } \\
\text { Knowledge (PMBOK) } \\
\text { em um projeto de } \\
\text { adequação de uma } \\
\text { Central de Materiais e } \\
\text { Esterilização aos } \\
\text { requisitos de qualidade } \\
\text { para acreditação }\end{array}$ & $\begin{array}{l}\text { O gerenciamento de } \\
\text { projetos possibilitou a } \\
\text { execução do projeto no } \\
\text { tempo e escopo previstos, } \\
\text { atendendo aos requisitos } \\
\text { de qualidade, permitindo } \\
\text { maior envolvimento e } \\
\text { comprometimento } \\
\text { equipe. }\end{array}$ \\
\hline PUBMED & A11 & $\begin{array}{l}\text { Biopreservation } \\
\text { and Biobanking }\end{array}$ & $\begin{array}{l}\text { Bjugn, R., \& Casati, } \\
\text { B., (2012) / Noruega }\end{array}$ & $\begin{array}{l}\text { Análise das partes } \\
\text { interessadas: uma } \\
\text { ferramenta útil para } \\
\text { o planejamento de } \\
\text { biobanco }\end{array}$ & $\begin{array}{l}\text { Revisar a teoria das } \\
\text { partes } \\
\text { relevantes }\end{array}$ & $\begin{array}{l}\text { A única coisa necessária, } \\
\text { porém, é uma vontade de } \\
\text { enfrentar possíveis fatores } \\
\text { negativos e riscos futuros, } \\
\text { uma vontade de se } \\
\text { envolver com pessoas que } \\
\text { podem ter pontos de vista } \\
\text { diferentes e uma vontade } \\
\text { de mudar os próprios } \\
\text { objetivos e / ou formas de } \\
\text { agir, se necessário para } \\
\text { atingir as metas gerais. }\end{array}$ \\
\hline EMERALD & A12 & $\begin{array}{l}\text { International } \\
\text { journal of health } \\
\text { care quality } \\
\text { assurance. }\end{array}$ & $\begin{array}{c}\text { Caccia-Bava, M. C., } \\
\text { Guimaraes, V. C., \& } \\
\text { Guimaraes, T., } \\
\text { (2013) / Estados } \\
\text { Unidos }\end{array}$ & $\begin{array}{c}\text { Fatores importantes } \\
\text { para o sucesso nas } \\
\text { fases do projeto } \\
\text { BPR do hospital }\end{array}$ & $\begin{array}{l}\text { Avaliar em que medida } \\
\text { os fatores de sucesso } \\
\text { propostos em um } \\
\text { hospital contribuem para } \\
\text { o sucesso de cada fase do } \\
\text { BPR. }\end{array}$ & $\begin{array}{l}\text { São feitas recomendações } \\
\text { para que os gerentes de } \\
\text { hospitais concentrem a } \\
\text { atenção e os recursos em } \\
\text { fatores importantes para o } \\
\text { sucesso do BPR. Os } \\
\text { gerentes de hospitais não } \\
\text { estão enfatizando as }\end{array}$ \\
\hline
\end{tabular}




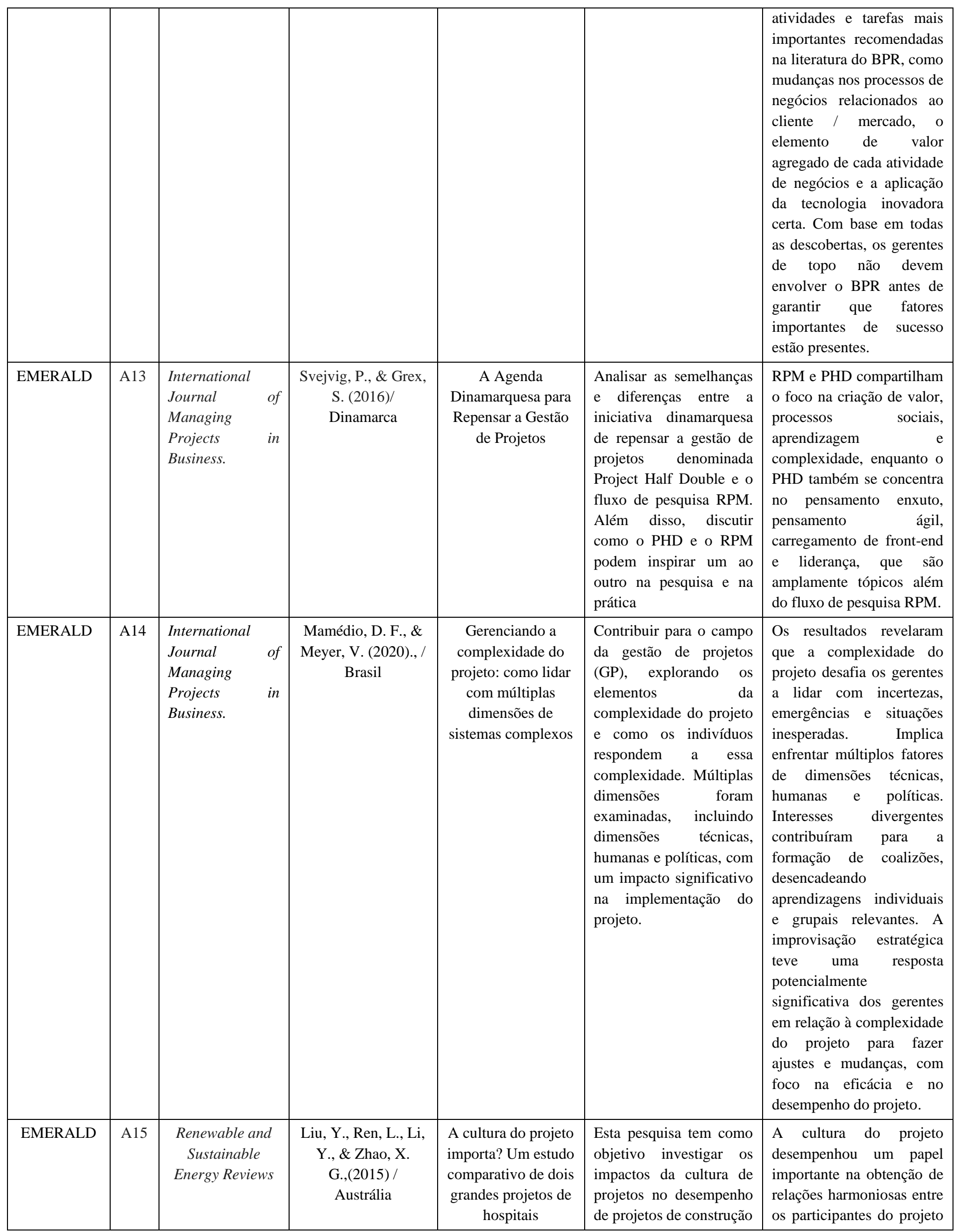




\begin{tabular}{|c|c|c|c|c|c|c|}
\hline & & & & & & $\begin{array}{l}\text { e melhores resultados do } \\
\text { projeto em termos de } \\
\text { cronograma, } \\
\text { funcionalidade, satisfação } \\
\text { com o processo, satisfação } \\
\text { com os relacionamentos, } \\
\text { questões ambientais } \\
\text { abordadas no sucesso } \\
\text { comercial, novas } \\
\text { oportunidades de negócios } \\
\text { e desempenho geral. O } \\
\text { Caso } 1 \text { superou o Caso } 2 \\
\text { nesses indicadores de } \\
\text { desempenho. Da mesma } \\
\text { forma, ficou claro que a } \\
\text { cultura do projeto deve ser } \\
\text { desenvolvida desde o } \\
\text { início e sustentada durante } \\
\text { o período do projeto. Além } \\
\text { disso, também foi } \\
\text { destacado que a cultura do } \\
\text { projeto deve ser traduzida } \\
\text { para todos os níveis da } \\
\text { cadeia de suprimentos, ou } \\
\text { seja, subcontratados e } \\
\text { fornecedores rat }\end{array}$ \\
\hline $\begin{array}{l}\text { Taylor e } \\
\text { Francys }\end{array}$ & A16 & $\begin{array}{c}\text { Journal of } \\
\text { Hospital } \\
\text { Librarianship, }\end{array}$ & $\begin{array}{l}\text { Kaur, A. (2018) / } \\
\text { Estados Unidos }\end{array}$ & $\begin{array}{c}\text { Avaliação do } \\
\text { aplicativo: Trello }\end{array}$ & $\begin{array}{l}\text { Avaliar o app Trello para } \\
\text { gestão de projetos para o } \\
\text { uso dos bibliotecários } \\
\text { hospitalares. }\end{array}$ & $\begin{array}{l}\text { Trello é uma ferramenta } \\
\text { baseada na Web que pode } \\
\text { tornar mais fácil para os } \\
\text { bibliotecários hospitalares } \\
\text { colaborar e gerenciar } \\
\text { projetos dentro e fora da } \\
\text { biblioteca e do hospital. A } \\
\text { versão gratuita do Trello } \\
\text { possui recursos que são } \\
\text { úteis para profissionais de } \\
\text { biblioteconomia e ciência } \\
\text { da informação e para } \\
\text { aqueles que colaboram } \\
\text { com profissionais de LIS. }\end{array}$ \\
\hline SAGE & A17 & $\begin{array}{c}\text { Project } \\
\text { Management } \\
\text { Journal }\end{array}$ & $\begin{array}{c}\text { Gordon, A., \& } \\
\text { Pollack, J. (2018) / } \\
\text { Canada }\end{array}$ & $\begin{array}{l}\text { Gerenciando a } \\
\text { integração de saúde: } \\
\text { adaptando o } \\
\text { gerenciamento de } \\
\text { projetos às } \\
\text { necessidades de } \\
\text { mudança } \\
\text { organizacional }\end{array}$ & $\begin{array}{l}\text { Contribuir para o fluxo } \\
\text { crescente de literatura } \\
\text { sobre gerenciamento de } \\
\text { projetos que explora a } \\
\text { combinação de } \\
\text { gerenciamento de } \\
\text { projetos e gerenciamento } \\
\text { de mudanças }\end{array}$ & $\begin{array}{l}\text { Com o escopo e a duração } \\
\text { mais longa do } \\
\text { envolvimento com um } \\
\text { projeto, pode ser mais } \\
\text { eficaz desenvolver } \\
\text { estruturas para a } \\
\text { combinação dessas } \\
\text { abordagens, enquadrando o } \\
\text { gerenciamento de projetos } \\
\text { dentro de um contexto de } \\
\text { gerenciamento } \\
\text { mudanças, do que o } \\
\text { contrário }\end{array}$ \\
\hline SCIELO & A18 & $\begin{array}{l}\text { Revista Gaúcha } \\
\text { de Enfermagem }\end{array}$ & $\begin{array}{c}\text { Cruz, J. R. D., } \\
\text { Gonçalves, L. S., \& } \\
\text { Giacomo, A. P. M. } \\
\text { D. A. D., (2019) / } \\
\text { Brasil }\end{array}$ & $\begin{array}{l}\text { Metodologia ágil } \\
\text { Scrum: uso pelo } \\
\text { enfermeiro } \\
\text { em jogo educativo }\end{array}$ & $\begin{array}{l}\text { Evidenciar o papel do } \\
\text { enfermeiro como gerente } \\
\text { de projeto nas fases de } \\
\text { planejamento } \\
\text { desenvolvimento de um }\end{array}$ & $\begin{array}{l}\text { Ao compartilhar sua } \\
\text { experiência clínica e } \\
\text { educacional, aliando as } \\
\text { competências gerenciais } \\
\text { desenvolvidas ao longo da }\end{array}$ \\
\hline
\end{tabular}




\begin{tabular}{|c|c|c|c|c|c|c|}
\hline & & & & $\begin{array}{l}\text { sobre manejo } \\
\text { seguro de } \\
\text { medicamentos }\end{array}$ & $\begin{array}{lr}\text { jogo educativo sobre } \\
\text { manejo seguro de } \\
\text { medicamentos } \\
\text { técnicos de enfermagem }\end{array}$ & $\begin{array}{l}\text { sua prática profissional, o } \\
\text { enfermeiro é capaz de } \\
\text { contribuir não só com o } \\
\text { conhecimento científico } \\
\text { sobre qualidade e } \\
\text { segurança do paciente, mas } \\
\text { também no gerenciamento } \\
\text { de projetos e alcance de } \\
\text { objetivos traçados em } \\
\text { equipe }\end{array}$ \\
\hline PUBMED & A19 & $\begin{array}{c}\text { Acta Informatica } \\
\text { Medica }\end{array}$ & $\begin{array}{c}\text { Safdari, R., } \\
\text { Ghazisaeidi, M., \& } \\
\text { Jebraeily, M. (2015) } \\
\text { / Tehran }\end{array}$ & $\begin{array}{l}\text { Electronic Health } \\
\text { Records: Critical } \\
\text { Success Factors in } \\
\text { Implementation }\end{array}$ & $\begin{array}{l}\text { Identificar os principais } \\
\text { fatores de sucesso do } \\
\text { RSE. }\end{array}$ & $\begin{array}{l}\text { O sucesso na } \\
\text { implementação dos EHRs } \\
\text { exige mais centralização } \\
\text { no gerenciamento de } \\
\text { projetos e nos fatores } \\
\text { humanos. Portanto, deve- } \\
\text { se criar a implementação } \\
\text { do roteiro de RSE, } \\
\text { estabelecer um trabalho de } \\
\text { equipe para a participação } \\
\text { dos usuários finais e } \\
\text { selecionar e preparar a } \\
\text { liderança, os usuários } \\
\text { obtêm treinamento } \\
\text { suficiente para usar o } \\
\text { sistema e também preparar } \\
\text { o suporte para manter e } \\
\text { promover o sistema. }\end{array}$ \\
\hline
\end{tabular}

Fonte: Autores (2021).

Após a escolha definitiva dos estudos a serem analisados na revisão, realizou-se a coleta de informações quantitativas (local de publicação, autor, ano de publicação e periódico) e informações qualitativas, como principais objetivos e resultados. Observa-se uma concentração de publicações no ano de 2019. Esse volume da artigos coincide com o ano subsequente a publicação do The Standard for Portfolio Management (PMI, 2018). O respectivo manual de boas práticas versa sobre orientação de gestão de portfólio de projetos nas organizações. A administração do portfólio é essencial para a sustentabilidade não apenas da gestão estratégica de um hospital, como também é muito importante para a manutenção do Escritório de Gerenciamento de projetos (Archibald, 2016).

No quadro e é possível observar que há países em que se concentra um número maior de pesquisas sobre a temática. O Canadá foi o país com maior número de pesquisas publicadas sobre experiências de gerenciamento de projetos e EGP no âmbito hospitalar. Apesar de número, é possível observar uma concentração de pesquisas sob autoria da pesquisadora Monique Aubry. Por outro lado, há estudo que comparou o nível de maturidade em gestão de projetos entre Brasil e Canadá e revelou que o Canadá apresenta o grau de maturidade maior (Júnior, 2010).

O presente estudo revela que Canadá não apenas se apresenta com o maior número de publicações, como também possui um número maior que os Estados Unidos - país em que foi criado o Project Management Institute (PMI), instituição que desenvolveu o guia de boas práticas de gerenciamento de projetos, o PMBOK (Project Management Body of Knowledge). O Gráfico 1 ilustra a distribuição das pesquisas de acordo com os respectivos países. 
Gráfico 1 - Distribuição por países.

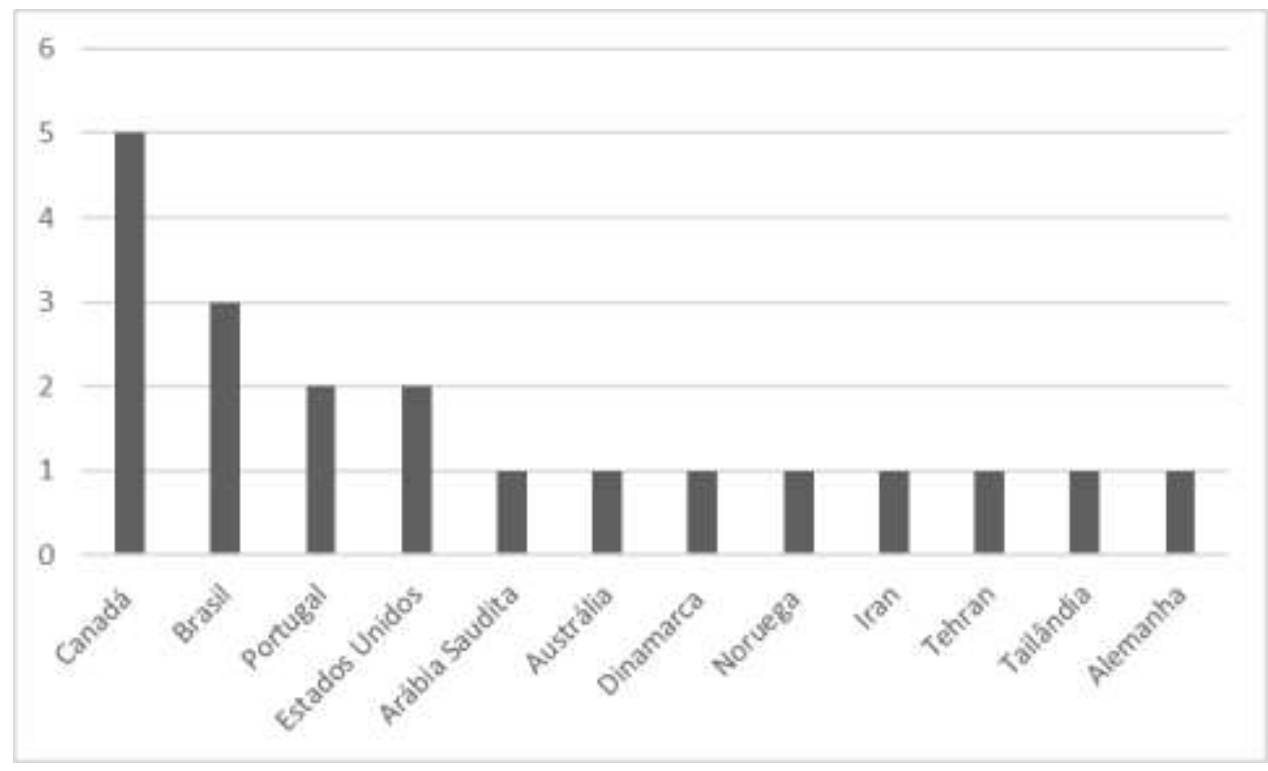

Fonte: Autores (2021).

No que se refere à comparação das evidências encontradas, é possível observar que o conceito de tipologia de EGP de Hill (2008) permeia todos os achados. A maior parte das evidências dispostas revela que as práticas de gerenciamento é o grupo que foi mais contemplado pelas boas práticas desenvolvidas nos hospitais, conforme o Gráfico 2.

Gráfico 2: Experiências de gerenciamento de projetos sob a perspectiva das funções de Hill (2008).

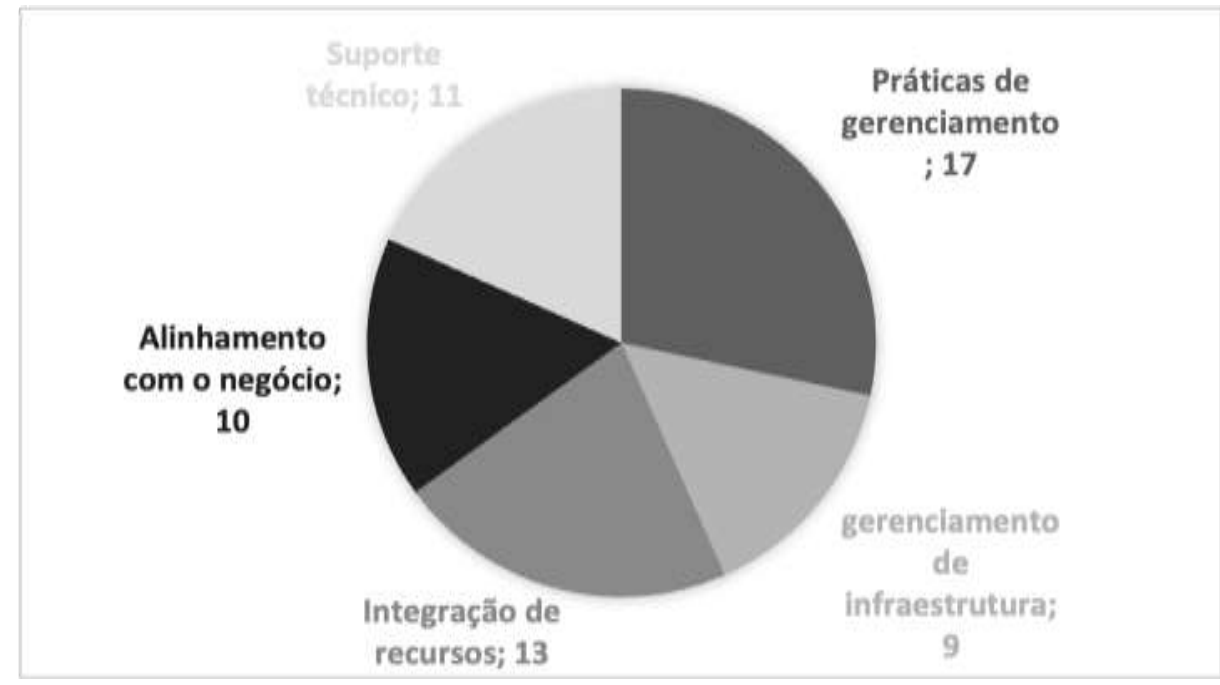

Fonte: Autores (2021).

Esse grupo contempla as seguintes funções: Metodologia de gerenciamento de projetos, ferramentas de gerenciamento de projetos, padrões e métricas, gerenciamento do conhecimento do projeto. Pesquisas corroboram com a visão do autor e das evidências ao compreender a tipologia de EGP de Hill como um conceito que pode servir de orientação para implantação de um EGP (Rad, Levin, 2002; Levin, 2010; Dai, Wells, 2004; Desouza, Evaristo, 2006; Andersen et al., 2007; Hobbs, Aubry, 2007; Artto et. al., 2011; Wysocki, 2013; Kerzner, 2017). A natureza do trabalho em gerenciamento de projetos, em especial no EGP, está associada ao uso constante de metodologias, das suas melhores práticas, da aplicação de indicadores, processos e tecnologias que permitem melhor desempenho (Barcui, 2012). Os demais grupos - gerenciamento de infraestrutura, integração 
de recursos, suporte técnico e alinhamento com o negócio - também são compreendidos nas experiências oriundas desta revisão. Isso evidencia uma coesão entre a prática e a teoria disposta na literatura. Outro aspecto que fez parte do escopo dessa pesquisa foi a organização das informações coletadas e a sua sumarização em três grupos: desafios, boas práticas e ferramentas e Tipologia de Hill (2008) conforme o Quadro 2.

Quadro 2: Desafios, boas práticas e ferramentas oriundas das pesquisas.

\begin{tabular}{|c|c|c|c|c|c|c|c|c|}
\hline \multirow[t]{2}{*}{$\mathbf{N}^{\mathbf{o}}$} & \multirow[t]{2}{*}{ Desafios } & \multirow[t]{2}{*}{ Boas práticas } & \multirow[t]{2}{*}{ Ferramentas } & \multicolumn{5}{|c|}{$\begin{array}{l}\text { Tipologia de Hill } \\
\text { (2008) }\end{array}$} \\
\hline & & & & 1 & 2 & 3 & 4 & 5 \\
\hline A1 & 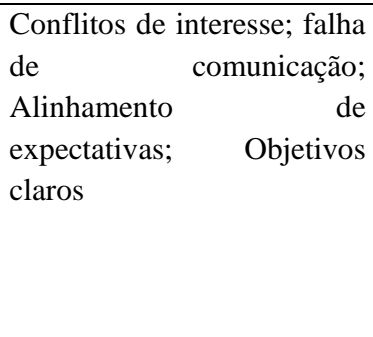 & $\begin{array}{l}\text { Profissionalismo em Gerenciamento de } \\
\text { projetos; Alinhamento estratégico; } \\
\text { instrumentos de gerenciamento de projetos } \\
\text { formalizados; Qualificação dos } \\
\text { profissionais em gerenciamento de projetos; } \\
\text { treinamento; gestão a nível de portfólio; } \\
\text { gestão de partes interessadas; gestão de } \\
\text { escopo }\end{array}$ & $\begin{array}{l}\text { Comunicação } r \text { bem } \\
\text { agendada; Treinamento } \\
\text { intensivo; } \quad \text { objetivos } \\
\text { compartilhados; análise } \\
\text { de desempenho periódico, } \\
\text { priorização de projetos }\end{array}$ & $\mathrm{X}$ & $\mathrm{X}$ & $\mathrm{X}$ & $X$ & $\mathrm{X}$ \\
\hline A2 & $\begin{array}{l}\text { Infraestrutura desatualizada; } \\
\text { informações dispersas; }\end{array}$ & $\begin{array}{l}\text { Gestão de Infraestrutura; Melhoria } \\
\text { contínua; Gestão do conhecimento; gestão } \\
\text { da comunicação; }\end{array}$ & $\begin{array}{l}\text { Escritório de projetos } \\
\text { como } \quad \text { coordenador; } \\
\text { Lições } \\
\text { treinamento; orientação } \\
\text { de projeto, PMO }\end{array}$ & $\mathrm{X}$ & $\mathrm{X}$ & $\mathrm{X}$ & $\mathrm{X}$ & $\mathrm{X}$ \\
\hline A3 & $\begin{array}{l}\text { Cultura organizacional; } \\
\text { falha na comunicação e } \\
\text { definição de papéis; }\end{array}$ & $\begin{array}{l}\text { Gestão de qualidade; gestão de partes } \\
\text { interessadas; gestão de comunicação; } \\
\text { Governança; negociação }\end{array}$ & $\begin{array}{l}\text { Estrutura organizacional; } \\
\text { Escritório de projetos } \\
\text { como coordenador e } \\
\text { plataforma de diálogo; } \\
\text { compreensão sistêmica; }\end{array}$ & $\mathrm{X}$ & $\mathrm{X}$ & & & $\mathrm{X}$ \\
\hline A4 & $\begin{array}{lcc}\text { Falta de supervisão } & \text { do } \\
\text { projeto; falta } & \text { de } \\
\text { transparência; falta } & \text { de } \\
\text { clareza dos indicadores } & \end{array}$ & $\begin{array}{l}\text { Governança; transparência; indicadores } \\
\text { claros; gestão de partes interessadas; gestão } \\
\text { de comunicação; gestão de portfólio; ciclo } \\
\text { de vida de gestão de projetos }\end{array}$ & $\begin{array}{l}\text { Governança de projetos, } \\
\text { programas e portfólio; } \\
\text { ISO21500; ISO21502 }\end{array}$ & $\mathrm{X}$ & $\mathrm{X}$ & $\mathrm{X}$ & $\mathrm{X}$ & \\
\hline A5 & $\begin{array}{l}\text { Má organização; falta de } \\
\text { maturidade em GP; }\end{array}$ & Governança; Gestão de infraestrutura & Implantação de PMO & & & & $\mathrm{X}$ & \\
\hline A6 & $\begin{array}{l}\text { Falha de comunicação; } \\
\text { Falha de planejamento; } \\
\text { Falha de monitoramento de } \\
\text { controle }\end{array}$ & $\begin{array}{l}\text { Gestão das partes interessadas; gestão da } \\
\text { comunicação; gestão de recursos; }\end{array}$ & $\begin{array}{l}\text { Documentos de gestão de } \\
\text { projetos; gráfico de } \\
\text { responsabilidade; detalhar } \\
\text { parâmetros de projeto; } \\
\text { business case; PMO; } \\
\text { Painel do projeto; Gannt, } \\
\text { Baseline, Estrutura } \\
\text { Analítica do Projeto; } \\
\text { Caminho crítico }\end{array}$ & $\mathrm{X}$ & $\mathrm{X}$ & $\mathrm{X}$ & $\mathrm{X}$ & $\mathrm{X}$ \\
\hline A7 & $\begin{array}{l}\text { Falha de planejamento, } \\
\text { dados não confiáveis; metas } \\
\text { irrealistas; falta de ambiente } \\
\text { sustentável no trabalho; } \\
\text { falta de técnica em } \\
\text { gerenciamento de projetos; } \\
\text { falta de autoridade; }\end{array}$ & $\begin{array}{l}\text { Gestão de partes interessadas; gestão do } \\
\text { conhecimento; Qualificação dos } \\
\text { profissionais em gerenciamento de projetos; } \\
\text { monitoramento e controle; gestão de } \\
\text { recursos; }\end{array}$ & $\begin{array}{l}\text { Envolvimento da equipe } \\
\text { de projeto; disseminação } \\
\text { de informações sobre o } \\
\text { projeto; uso de dados } \\
\text { confiáveis; software; } \\
\text { lições aprendidas }\end{array}$ & & $\mathrm{X}$ & & $\mathrm{X}$ & $\mathrm{X}$ \\
\hline
\end{tabular}




\begin{tabular}{|c|c|c|c|c|c|c|c|c|}
\hline & envolvimento político & & & & & & & \\
\hline A8 & $\begin{array}{l}\text { Falta de informações de } \\
\text { projetos pretéritos; }\end{array}$ & $\begin{array}{l}\text { Profissionalismo em Gerenciamento de } \\
\text { projetos; liderança; gestão de portfólio, } \\
\text { gestão do conhecimento; gestão de } \\
\text { indicadores }\end{array}$ & $\begin{array}{lrr}\text { PMO; } & \text { sistema de } \\
\text { informação de portfólio e } \\
\text { registros; } & \text { modelo de } \\
\text { liderança } & \text { distribuído; } \\
\text { treinamento; ferramenta } \\
\text { de processo de } & \text { projeto; } \\
\text { manutenção } & \text { de } \\
\text { repositório de registros de } \\
\text { projetos e r lições } \\
\text { aprendidas }\end{array}$ & $\mathrm{X}$ & $\mathrm{X}$ & & & $\mathrm{X}$ \\
\hline A9 & $\begin{array}{l}\text { Competitividade } \\
\text { desempenho }\end{array}$ & $\begin{array}{l}\text { Gestão das dez áreas de gestão do } \\
\text { conhecimento; gestão da inovação }\end{array}$ & N/A & & $\mathrm{X}$ & & & \\
\hline A10 & $\begin{array}{l}\text { Mudanças } \\
\text { sociais e tecnológicas; } \\
\text { demandas; qualidade nos } \\
\text { serviços de saúde; aumento } \\
\text { crescente dos custos } \\
\text { assistenciais, escassez de } \\
\text { investimentos e uso } \\
\text { ineficiente dos recursos }\end{array}$ & $\begin{array}{l}\text { Melhoria contínua; Profissionalismo em } \\
\text { Gerenciamento de projetos; gestão das } 10 \\
\text { áreas de conhecimento }\end{array}$ & $\begin{array}{l}\text { Estrutura organizacionais; } \\
\text { metodologia de gestão de } \\
\text { projetos; documentação } \\
\text { formal }\end{array}$ & & $\mathrm{X}$ & & & \\
\hline A11 & $\begin{array}{l}\text { Conflito de interesse; } \\
\text { sustentabilidade a longo } \\
\text { prazo; identificar e envolver } \\
\text { as partes interessadas em } \\
\text { um projeto; clareza de } \\
\text { objetivos }\end{array}$ & $\begin{array}{l}\text { Ciclo de vida de gestão de projetos; } \\
\text { transparência; Gestão das dez áreas de } \\
\text { conhecimento }\end{array}$ & $\begin{array}{l}\text { Documentação formal; } \\
\text { matriz de gestão de partes } \\
\text { interessadas; }\end{array}$ & $\mathrm{X}$ & $\mathrm{X}$ & $\mathrm{X}$ & & \\
\hline A12 & $\begin{array}{l}\text { Percepção arcaica a respeito } \\
\text { da gestão; comunicação; }\end{array}$ & $\begin{array}{l}\text { Planejamento; mapeamento de processos de } \\
\text { gestão de projetos; gestão da comunicação; } \\
\text { Melhoria contínua; gestão de recursos; } \\
\text { informatização; liderança }\end{array}$ & $\begin{array}{l}\text { Plano de ação; feedback; } \\
\text { estrutura do projeto; } \\
\text { business case; reunião } \\
\text { periódica envolvendo; } \\
\text { avaliação dos benefícios } \\
\text { do projeto; avaliação de } \\
\text { viabilidade; seleção de } \\
\text { projetos; definição de } \\
\text { processo; otimização de } \\
\text { processo; }\end{array}$ & $\mathrm{X}$ & $\mathrm{X}$ & $\mathrm{X}$ & $\mathrm{X}$ & $\mathrm{X}$ \\
\hline A13 & Complexidade dos projetos & 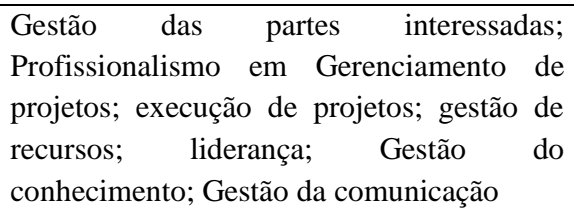 & $\begin{array}{l}\text { Metodologia de gestão de } \\
\text { projetos; treinamento; } \\
\text { brainstorming; } \\
\text { dashboard; lição } \\
\text { aprendida }\end{array}$ & $\mathrm{X}$ & $\mathrm{X}$ & $\mathrm{X}$ & & $\bar{X}$ \\
\hline A14 & 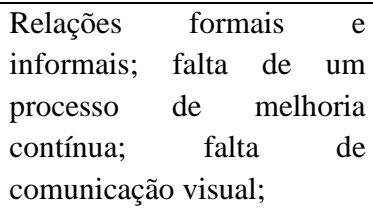 & $\begin{array}{l}\text { Profissionalismo em Gerenciamento de } \\
\text { projetos; informatização; liderança; } \\
\text { negociação; gestão do conhecimento; } \\
\text { melhoria contínua; ciclo de vida do projeto; } \\
\text { gestão das } 10 \text { áreas; }\end{array}$ & $\begin{array}{l}\text { Gerenciamento } r \\
\text { organização dos dados; } \\
\text { equipe exclusiva para o } \\
\text { projeto; lições aprendidas }\end{array}$ & $\mathrm{X}$ & $\mathrm{X}$ & $\mathrm{X}$ & & $\mathrm{X}$ \\
\hline A15 & N/A & $\begin{array}{l}\text { Cultura de gerenciamento de projetos; } \\
\text { gestão das partes interessadas; alinhamento }\end{array}$ & $\begin{array}{l}\text { Projeto } \quad \text { orientado à } \\
\text { resultados; } \quad \text { Resultados }\end{array}$ & & $\mathrm{X}$ & & & $\mathrm{X}$ \\
\hline
\end{tabular}




\begin{tabular}{|c|c|c|c|c|c|c|c|c|}
\hline & & estratégico Monitoramento e controle & $\begin{array}{lr}\text { orientados às } & \text { pessoas; } \\
\text { flexibilidade } & \text { nos } \\
\text { processos } & \end{array}$ & & & & & \\
\hline A16 & Sobrecarga de informação & Informatização; Kanban & $\begin{array}{l}\text { Trello; One note; } \\
\text { Microsoft planner; Zolo }\end{array}$ & & & $\mathrm{X}$ & & \\
\hline A17 & N/A & $\begin{array}{l}\text { Gestão das dez áreas de conhecimento; } \\
\text { fatores críticos de sucesso; liderança; } \\
\text { informatização; Kanban }\end{array}$ & $\begin{array}{l}\text { Análise de desempenho; } \\
\text { equilíbrio dos fatores } \\
\text { críticos de sucesso com o } \\
\text { ponto de vista da parte } \\
\text { interessada; identificação } \\
\text { do líder; }\end{array}$ & $\mathrm{X}$ & $\mathrm{X}$ & $\mathrm{X}$ & & $\mathrm{X}$ \\
\hline A18 & $\begin{array}{l}\text { Transformar o processo de } \\
\text { aprendizagem, tornando-o } \\
\text { mais interativo } \\
\text { significativo }\end{array}$ & $\begin{array}{l}\text { Metodologia ágil; liderança, gestão de } \\
\text { comunicação }\end{array}$ & Scrum & & $\mathrm{X}$ & & & \\
\hline A19 & Comunicação entre setores & $\begin{array}{l}\text { Liderança; Gestão das dez áreas de } \\
\text { conhecimento; alinhamento estratégico; }\end{array}$ & $\begin{array}{l}\text { Utilização de dados } \\
\text { confiáveis; troca de } \\
\text { informação entre setores; } \\
\text { infraestrutura de rede de } \\
\text { informação }\end{array}$ & & $\mathrm{X}$ & $\mathrm{X}$ & X & \\
\hline
\end{tabular}

*1 Alinhamento com negócio; *2 Práticas de Gerenciamento; *3 Suporte técnico; *4 Infraestrutura; *5 Gestão de recursos. Fonte: Autores (2021).

Uma prática de administração de projetos pode ser compreendida como uma atividade profissional ou de gestão que contribui para execução de um processo e que pode empregar uma ou mais técnicas e ferramentas (Mamédio, 2021). A primeira coluna mostra as categorias de melhores práticas construídas a partir dos dados extraídos das evidências apresentadas na segunda coluna. A principal vantagem na associação entre a gestão hospitalar e a gestão de projetos encontra-se na diversidade de métodos que a segunda tem a oferecer ao específico contexto hospitalar (Getirana, 2020). No entanto, a implantação de metodologias de gestão de projetos no ambiente hospitalar não é trivial. Os hospitais, enquanto organizações baseadas em processos, carecem de maturidade em gerenciamento de projetos, uma variável considerada bastante significativa (Bitencourt, 2020).

No intuito de alcançar a maturidade em gerenciamento de projetos em hospitais, a presença de um EGP poderia facilitar esse processo de acordo com as evidências encontradas. Destaca-se cinco vertentes das funções do EGP: práticas de gerenciamento como também da perspectiva da informatização, da visão e alinhamento estratégico, da infraestrutura integração de recursos, suporte técnico. As evidências coletadas revelam a importância das cinco funções que compõem a Tipologia de Hill (2008) ao se demonstrarem aderentes, seja em sua totalidade ou de forma parcial, a todas as experiências encontradas nessa revisão integrativa. Destaca-se que a revisão realizada chama atenção para a seleção de apenas uma pesquisa da área de metodologia ágil (Cruz, 2019). Entretanto, as demais evidências abordam temáticas oriundas da visão preditiva como o PMBOK (PMI, 2017), embora este não seja uma metodologia, mas um guia de boas práticas que pode servir de base para o desenvolvimento de uma metodologia na organização.

As ferramentas utilizadas na gestão de projetos de hospitais estão resumidas no Quadro 2. O PMBOK (2017) conceitua ferramenta como "alguma coisa tangível, como um modelo ou um programa de software usado para execução de uma atividade para produzir um produto ou resultado". O conjunto de pesquisas coletadas evidenciou que o EGP é, junto com as lições aprendidas, a ferramenta mais utilizada em hospitais como solução para a administração dos projetos, programas e 
portfólios. As lições aprendidas são unanimidade entre todos os administradores de EGP como relevante contribuição durante o encerramento, desde que disseminadas de forma correta (Amaral, 2021). Seu papel como agente mobilizador para executar as atividades de lições aprendidas e compilação das melhores práticas (Silva, 2021). Encaminha o resultado das discussões para uma base de conhecimento que possa ser acessada em projetos posteriores (Menezes, 2009).

\section{Conclusão}

Ao analisar os 41 desafios levantados, é possível constatar alguns pontos relevantes. A falha em comunicação é o aspecto mais levantado nas pesquisas como sendo um problema a ser solucionado pelos administradores hospitalares. Há um aspecto a se considerar sobre essa evidência que é o fato dela estar relacionada com outros elementos levantados nas pesquisas a respeito dos desafios coletados. A falha de comunicação se relaciona diretamente e indiretamente com: falta de alinhamento de expectativas (Schultz et. al., 2019), conflito de interesses (Schultz et. al., 2019; Bjugn, 2012), clareza de objetivos (Bjugn, 2012) informação dispersa (Aubry, 2018), falta de transparência (Do Rosário, 2014) sobrecarga de informações (KAUR, 2018), falta de comunicação visual (Mamédio, 2020), relações formais e informais (Mamédio, 2020), identificação e envolvimento das partes interessadas (Bjugn, 2012), falta de informações sobre projetos pretéritos (Giasson, 2019) e cultura organizacional (Aubry, 2014). Isso evidencia a importância de ações que busquem mitigar riscos na comunicação, bem como usar em favor dos resultados do projeto.

Uma pesquisa (Giasson, 2019) oferece uma nova ferramenta de medição, enfatizando a importância de todas as dez áreas de gestão do conhecimento na gestão hospitalar e apresentando-as como as principais categorias no processo de inovação ao buscar conscientizar os gestores sobre a importância da análise profissional, utilizando os itens desenvolvidos como uma nova ferramenta em formato de questionário.

Os principais achados desta revisão mostram que o gerenciamento de projetos e EGP se tornaram presente em vários aspectos nas práticas gerenciais dos hospitais ao redor do mundo. Embora todas as práticas contemplem de alguma maneira as funções dispostas da literatura de Hill (2008), nem todas estão contempladas dentro do contexto de um EGP.

Um estudo (Schultz, 2019) identificou que a importância do profissionalismo na gestão de projetos e que os hospitais são mais capazes de implementar inovações médicas e expandir o escopo de seu portfólio de serviços médicos se tiverem um alto nível de profissionalização em gerenciamento de projetos. Apesar disso, outro estudo (Saleem, 2020) evidenciou que os gerentes de projeto enfrentam vários problemas, desde o estágio de iniciação do projeto até o seu encerramento devido à estrutura burocrática rígida, falta de autonomia para os gestores, falta de experiência em gerenciamento de projetos e decisões políticas.

Ao aprofundar no espectro do PMO, é possível destacar um estudo (Santos, 2015) que revela que a construção de um Escritório de projetos é um elemento chave para a profissionalização e descentralização da gestão de projetos. Os benefícios surgem da incorporação dos gerentes de projeto em unidades de portfólio. Esses benefícios incluíram (1) gerentes de projeto que desenvolvem relacionamentos colaborativos, compreenderam o negócio, a governança e se acostumaram a entregar no ambiente de destino; (2) agilidade na tomada de decisões e a capacidade de gerir com mais eficácia as mudanças do projeto; e (3) menos sobrecarga de PMO central devido aos gerentes de projeto reportando em portfólios, com economia especialmente no espaço de relatório, uma vez que relatórios e governança menos centralizados são obrigatórios.

Outro estudo (Aubry et. al., 2018) reitera a importância do PMO durante grandes mudanças em uma organização de saúde, a fim de limitar os altos níveis de rotatividade: mandato claro do PMO alocação do líder do PMO, alocação dos recursos certos, apoio da alta administração, centro de apoio disponível à linha de frente e apoio a todo o ciclo de vida do projeto.

As temáticas relevantes no âmbito da gestão de projetos no cenário hospitalar estão associadas aos desafios nas mais diversas áreas do conhecimento gerencial, em especial, nas dez áreas de conhecimento da gestão de projetos. Porém, não se restringe a isso. Os artigos que compõem o núcleo de elegibilidade deixam bem claro que as experiências implementadas nos 
hospitais abarcam práticas que surgem como respostas a desafios, não apenas das práticas de gerenciamento (metodologia, ferramentas, padrões e métricas e gestão do conhecimento), como também da perspectiva da informatização, da visão e alinhamento estratégico, da infraestrutura (governança, avaliação, organização e estrutura), integração de recursos (gestão de recursos e treinamento) suporte técnico (mentoria, planejamento, recuperação do projeto e auditoria do projeto) (Hill, 2008).

O artigo evidencia, a partir de uma revisão integrativa, a importância do PMO como núcleo de apoio ao gerenciamento de projetos e à consolidação da governança da gestão de projetos no hospital, de modo a decentralizar as tomadas de decisões. Ressalta ainda a importância das funções do PMO para a profissionalização da administração de projetos no âmbito hospitalar, pois remete à práticas e ferramentas que supre os desafios como: infraestrutura desatualizada; informações dispersas, má organização; falta de maturidade em gestão de projetos, falha de comunicação; falha de planejamento; falha de monitoramento de controle e falta de informações de projetos pretéritos.

Avaliando a proposta inicial desta revisão, observa-se lacunas na investigação relacionadas ao gerenciamento de programas dentro do portfólio de projetos e programas dos hospitais. Apesar das palavras-chave selecionadas incluir diferentes tipos de abordagens de Escritório de gerenciamento de projetos, somente se localizou artigos referentes a gestão de projetos, os quais preencheram os critérios de inclusão previamente estabelecidos.

Os fatores que intermediam essa lacuna escapam do âmbito desta revisão, no entanto, parece claro que, como é possível localizar publicações, as quais indicam a possibilidade de ocorrência de administração de programas decorrentes da carteira do EGP, há a necessidade dos hospitais implementarem a gestão de programas e, portanto, a necessidade do desenvolvimento de pesquisas sobre a o impacto dessa administração.

Frente às lacunas evidenciadas e os resultados apontados nos artigos incluídos nesta revisão integrativa, entende-se ser necessário intensificar esforços para o desenvolvimento de pesquisas com delineamentos que produzam evidências fortes relativas ao tema investigado, principalmente na realidade da prática da administração de programas no âmbito hospitalar.

\section{Referências}

Almeida, N. D. O. (2018). Gerenciamento de portfólio e PMO. Editora FGV.

Amaral, J. A. A. D. (2021). Usando aprendizagem baseada em projetos para ensinar aprendizagem baseada em projetos: as lições aprendidas. Pro-Posições, 32 .

Archibald, R. D., \& Archibald, S. (2016). Leading and managing innovation: What every executive team must know about project, program, and portfolio management. Auerbach Publications.

Assis, S. S. D. (2021). Desenvolvimento de um modelo de monitoramento de produtos para os Escritórios de Gerenciamento de Projetos em saúde em uma organização pública federal (Doctoral dissertation).

Aubry, M., Richer, M. C., \& Lavoie-Tremblay, M. (2014). Governance performance in complex environment: The case of a major transformation in a university hospital. International Journal of Project Management, 32(8), 1333-1345.

Bitencourt, K. D. C. B. (2020). Estudo dos desafios e limitações para a implantação da Gestão de Custos em um hospital privado de médio porte do Sul de Minas Gerais: projeto de Intervenção.

Bjugn, R., \& Casati, B. (2012). Stakeholder analysis: a useful tool for biobank planning. Biopreservation and Biobanking, 10(3), $239-244$.

Caccia-Bava, M. C., Guimaraes, V. C., \& Guimaraes, T. (2013). Important factors for success in hospital BPR project phases. International journal of health care quality assurance.

Cruz, J. R. D., Gonçalves, L. S., \& Giacomo, A. P. M. D. A. D. (2019). Metodologia ágil Scrum: uso pelo enfermeiro em jogo educativo sobre manejo seguro de medicamentos. Revista Gaúcha de Enfermagem, 40.

do Rosário Bernardo, M. (2014). Project indicators for enhancing governance of projects. Procedia Technology, $16,1065-1071$.

dos Anjos, N. D. S. T., \& Portilho, B. C. R. Elaboração da pergunta de pesquisa. Universidade de Brasília-Editora ECoS Faculdade de Ciências da Saúde, 73.

Fonseca, G. L. M. (2021). Escritório de projetos em organizações públicas: análise do desempenho e da aderência à estratégia empresarial. Brazilian Journal of Business, 3(2).

Freire, E. M. R., Batista, R. C. R., \& Martinez, M. R. (2016). Gerenciamento de projetos voltado para acreditação hospitalar: estudo de caso. Online Brazilian Journal of Nursing, 15(1), 96-108. 
Getirana, J. V. (2020). Analise do perfil dos usuários pediátricos de uma OMS, na gestão de projetos para melhoria do serviço.

Ghasemi, M., Nejad, M. G., \& Bagzibagli, K. (2017). Knowledge management orientation: an innovative perspective to hospital management. Iranian journal of public health, 46(12), 1639 .

Giasson, L. (2019). The Best of Both Models: Key Components of a Successful Hybrid Project Management Office Model in a Health Care Organization. The health care manager, 38(3), 247-252.

Gordon, A., \& Pollack, J. (2018). Managing healthcare integration: Adapting project management to the needs of organizational change. Project Management Journal, 49(5), 5-21.

Hill, G. M. (2007). The complete project management office handbook. Auerbach Publications.

Junior, J. T. P., do Carmo Satller, T., Pereira, A. G., \& Silva, L. C. (2021). A importância de um escritório de gerenciamento de projetos em uma organização. Revista Produção Online, 21(2), 353-371.

Kaur, A. (2018). App Review: Trello. Journal of Hospital Librarianship, 18(1), 95-101.

Lavoie-Tremblay, M., Aubry, M., Richer, M. C., \& Guylaine, C. Y. R. (2018). A health care project management office's strategies for continual change and continuous improvement. The health care manager, 37(1), 4-10.

Mamédio, D. F., \& Meyer, V. (2020). Managing project complexity: how to cope with multiple dimensions of complex systems. International Journal of Managing Projects in Business.

Moher, D., Liberati, A., Tetzlaff, J., Altman, D. G., \& Prisma Group. (2009). Preferred reporting items for systematic reviews and meta-analyses: the PRISMA statement. PLoS medicine, 6(7), e1000097.

de Oliveira, J. M., de Almeida Jurach, G., Pinto, R. S., \& Kerchirne, L. M. (2017). Project offices and the federal universities: A study on project management in the context of higher education institutions. Revista de Gestão e Projetos, 8(3), 18-28.

Oliveira, R. R., \& Martins, H. C. (2020). Desempenho do escritório de gerenciamento de projetos. Innovar: Revista de ciencias administrativas y sociales, 30(75), 119-134.

PMI, P., \& PMI. (2017). Um guia do conhecimento em gerenciamento de projetos (Guia PMBOK). In Project Management Institute (pp. 385-405).

PMI, P., \& PMI. (2018). The standard for portfólio 4 ed. In Newtown Square.

Safdari, R., Ghazisaeidi, M., \& Jebraeily, M. (2015). Electronic health records: critical success factors in implementation. Acta Informatica Medica, 23(2), 102.

Saleem, F., Murtaza, I., Hyder, S., \& Malik, M. I. (2020). Public Health and Project Management: Do Projects Deliver?. International Journal of Environmental Research and Public Health, 17(19), 7244.

Santos, V., \& Varajão, J. (2015). PMO as a key ingredient of public sector projects' success-position paper. Procedia computer science, 64, $1190-1199$.

Silva, C., \& Resende, M. D. (2021). Gestão Do Conhecimento E Aprendizagem Na Gestão De Projetos Gestão do Conhecimento e Aprendizagem. Brazilian Journal of Development, 7(3), 25816-25834.

Liu, Y., Ren, L., Li, Y., \& Zhao, X. G. (2015). The industrial performance of wind power industry in China. Renewable and Sustainable Energy Reviews, 43, 644-655.

Srivannaboon, S., \& Southall, P. (2011). An exploratory study of the value of project management for hospital administration in Thailand. Journal of General Management, 36(4), 53-69.

Svejvig, P., \& Grex, S. (2016). The Danish agenda for rethinking Project management. International Journal of Managing Projects in Business.

Aubry, M., Richer, M. C., \& Lavoie-Tremblay, M. (2014). Governance performance in complex environment: The case of a major transformation in a university hospital. International Journal of Project Management, 32(8), 1333-1345. 